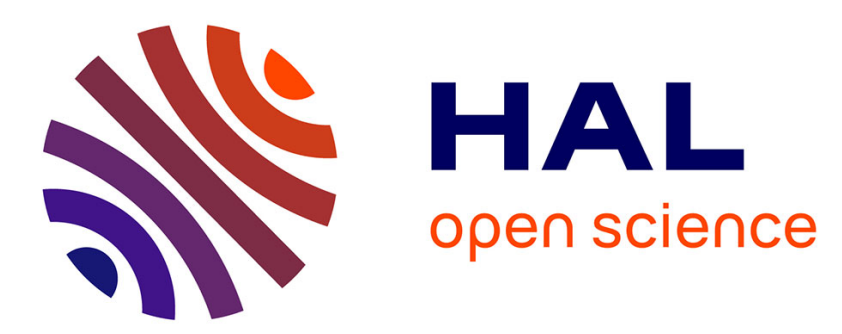

\title{
Carbon dioxide transport in molten calcium carbonate occurs through an oxo-Grotthuss mechanism via a pyrocarbonate anion
}

\author{
Dario Corradini, François-Xavier Coudert, Rodolphe Vuilleumier
}

\section{- To cite this version:}

Dario Corradini, François-Xavier Coudert, Rodolphe Vuilleumier. Carbon dioxide transport in molten calcium carbonate occurs through an oxo-Grotthuss mechanism via a pyrocarbonate anion. Nature Chemistry, 2016, 8 (5), pp.454-460. 10.1038/nchem.2450 . hal-02113318

\author{
HAL Id: hal-02113318 \\ https://hal.science/hal-02113318
}

Submitted on 28 Apr 2019

HAL is a multi-disciplinary open access archive for the deposit and dissemination of scientific research documents, whether they are published or not. The documents may come from teaching and research institutions in France or abroad, or from public or private research centers.
L'archive ouverte pluridisciplinaire HAL, est destinée au dépôt et à la diffusion de documents scientifiques de niveau recherche, publiés ou non, émanant des établissements d'enseignement et de recherche français ou étrangers, des laboratoires publics ou privés. 


\title{
Carbon dioxide transport in molten calcium carbonate occurs through an oxo-Grotthuss mechanism via a pyrocarbonate anion
}

Dario Corradini, ${ }^{1,2,3}$ François-Xavier Coudert, ${ }^{4, *}$ and Rodolphe Vuilleumier ${ }^{1,2,3, \dagger}$

${ }^{1}$ Department of Chemistry, École Normale Supérieure - PSL Research University, 24 rue Lhomond, 75005 Paris, France

${ }^{2}$ Sorbonne Universités, UPMC Univ. Paris 06, PASTEUR, 75005 Paris, France

${ }^{3}$ CNRS, UMR 8640 PASTEUR, 75005 Paris, France

${ }^{4}$ PSL Research University, Chimie ParisTech - CNRS, Institut de Recherche de Chimie Paris, 75005 Paris, France

\begin{abstract}
The reactivity, speciation and solvation structure of $\mathrm{CO}_{2}$ in carbonate melts are relevant both for the fate of carbon in deep geological formations and for its electroreduction to $\mathrm{CO}$, to be used as fuel, by means of solvation in a molten carbonate electrolyte. In particular, the high solubility of $\mathrm{CO}_{2}$ in carbonate melts has been tentatively attributed to the formation of a new carbon species, the pyrocarbonate anion, $\mathrm{C}_{2} \mathrm{O}_{5}^{2-}$. In this work we study, by first principles molecular dynamics simulations, the behaviour of $\mathrm{CO}_{2}$ in molten calcium carbonate. We find that pyrocarbonate forms spontaneously and the identity of the $\mathrm{CO}_{2}$ molecule is quickly lost through $\mathrm{O}^{2-}$ exchange. The transport of $\mathrm{CO}_{2}$ in this molten carbonate thus occurs in a fashion similar to the Grotthuss mechanism in water, and is three times faster than molecular diffusion. This shows that Grotthusslike transport is more general than thought so far.
\end{abstract}

\footnotetext{
* fx.coudert@chimie-paristech.fr

$\dagger$ Rodolphe.Vuilleumier@ens.fr
} 
Carbonatite melts, mostly composed of $\mathrm{XCO}_{3}\left(\mathrm{X}=\mathrm{Li}_{2}, \mathrm{Na}_{2}, \mathrm{~K}_{2}, \mathrm{Mg}\right.$, Ca), have recently received a good deal of attention $[1,2]$. In fact they have been proposed to be the most conductive phase in Earth's upper mantle. Carbonatite melts may determine the mobility and long-term storage of deep carbon in Earth, especially if they are found in the lower mantle [3-5]. Estimations based on conductivity data have led to propose a $0.035-0.35 \%$ content of carbonatites by volume in the asthenosphere, in line with the estimated $\mathrm{CO}_{2}$ content in magmas [1]. Carbon dioxide from geological formations is mostly released into the atmosphere during volcanic activity, although the efficiency of $\mathrm{CO}_{2}$ degassing remains poorly known [6]. Despite the importance of $\mathrm{CO}_{2}$ species for the deep carbon cycle [7], the reactivity, speciation and solvation structure of $\mathrm{CO}_{2}$ in carbonatite melts have so far remained unexplored.

New technologies capable of reducing the carbon footprint are highly demanded, in particular in order to limit the impact of $\mathrm{CO}_{2}$ on the environment. One of the strategies considered in the context of carbon capture and valorisation consists in its dissolution in a molten carbonate medium and its subsequent electroreduction to CO [8-10]. Therefore the interaction between $\mathrm{CO}_{2}$ and carbonates is relevant for environmental science and engineering beyond geochemistry.

In the context of the electrochemical reduction of $\mathrm{CO}_{2}$, it has been observed that the solubility of $\mathrm{CO}_{2}$ in the carbonate electrolyte is higher than what one could expect simply from $x_{\mathrm{CO}_{2}}^{l}=k_{H} P_{\mathrm{CO}_{2}}$, where $x_{\mathrm{CO}_{2}}^{l}$ is the concentration of $\mathrm{CO}_{2}$ in the liquid, $k_{H}$ is Henry's constant and $P_{\mathrm{CO}_{2}}$ is $\mathrm{CO}_{2}$ partial pressure. In order to explain this increased solubility, a reaction of $\mathrm{CO}_{2}$ with the carbonate anion has been hypothesised:

$$
\mathrm{CO}_{2}+\mathrm{CO}_{3}^{2-} \rightleftharpoons \mathrm{C}_{2} \mathrm{O}_{5}^{2-}
$$

with the product of the reaction being named pyrocarbonate (or dicarbonate) [8-10]. Taking $K_{\text {pyro }}$ as the equilibrium constant of this chemical reaction, one can then define an apparent Henry's constant $k_{H}^{\text {app }}=\left(1+K_{\text {pyro }}\right) k_{H}$. Thus it is possible that the $\mathrm{CO}_{2} /$ pyrocarbonate equilibrium controls the solubility of $\mathrm{CO}_{2}$ in molten carbonates. While this equilibrium can contribute to a larger $\mathrm{CO}_{2}$ uptake in molten carbonates, it is not clear whether this is favourable for electrochemical processes, as the $\mathrm{CO}_{2}$ involved in pyrocarbonate may not be readily accessible depending on the rate of interconversion. It is thus crucial to obtain a better understanding of $\mathrm{CO}_{2}$ solvation in molten carbonates at the molecular level. 
A limited number of previous studies have provided some support to the possibility of the formation of pyrocarbonate. The existence of a $\mathrm{CO}_{2} /$ pyrocarbonate equilibrium has been first hypothesised by Claes et al. on the basis of experiments performed on the Li-Na-K carbonate eutectic mixture [11]. This has been also supported by gas phase calculations [12]. It has later been shown, by density functional theory (DFT) calculations, that in the gas phase $\mathrm{C}_{2} \mathrm{O}_{5}^{2-}$ and larger oligomers $\mathrm{C}_{n} \mathrm{O}_{2 n+1}^{2-}$ are structurally stable with their energetics strongly dependent on the counterion [13]. Polymeric phases of $\mathrm{CO}_{2}$ have been also predicted by DFT [14]. Zhang et al. have proposed evidence of the presence of pyrocarbonate in Raman spectroscopy experiments performed exposing molten carbonates mixtures to a $\mathrm{CO}_{2}$ atmosphere [15]. Finally, pyrocarbonate has been also invoked to explain NMR spectra in aqueous carbonate solutions [16].

Recently, two first principles molecular dynamics (FPMD) studies have addressed the properties of molten carbonates [17] and of $\mathrm{CO}_{2}$ in silicate melts [18]. The first has provided relevant information for the study of liquid $\mathrm{CaCO}_{3}$, until then poorly known by experiments, such as the liquid structure, density, atomic vibration motions, diffusion coefficients and electrical conductivity. In the second one, the speciation of $\mathrm{CO}_{2}$ in basaltic and kimberlitic melts in the $\mathrm{CaO}-\mathrm{MgO}-\mathrm{Al}_{2} \mathrm{O}_{3}-\mathrm{SiO}_{2}$ system has been investigated. Importantly, the formation of $\mathrm{C}_{2} \mathrm{O}_{5}^{2-}$ has been observed in the basaltic melt, accounting for $\simeq 3.7 \%$ of the $\mathrm{C}$ content in the system. Pyrocarbonate has been found to be a transient species with a very short mean life time of 175 fs, too short to assess its solvation structure and formation/dissociation dynamics.

In this study, we focus on $\mathrm{CO}_{2}$ in molten $\mathrm{CaCO}_{3}$, with the aim of characterising the formation/dissociation of the pyrocarbonate and the solvation structure of $\mathrm{CO}_{2}$ and pyrocarbonate in the melt. Using FPMD simulations, we confirm the presence of pyrocarbonate which exists in rapid exchange with separate $\mathrm{CO}_{2}$ and carbonate. The pyrocarbonate ion lives longer in $\mathrm{CaCO}_{3}$ than in the basaltic melt reported in Ref. [18], allowing us to study the details of its solvation structure, beyond its geometry. In addition, we find that the transport of $\mathrm{CO}_{2}$ in molten carbonate occurs in a similar fashion to the Grotthuss mechanism for proton transport in water, via independent events of formation and dissociation of the pyrocarbonate molecule. 


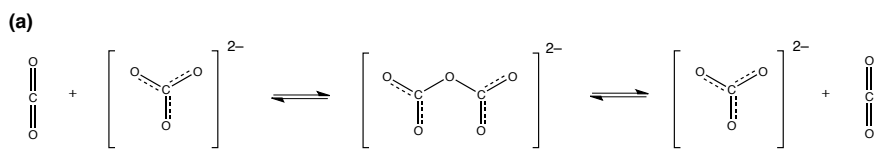

(b)

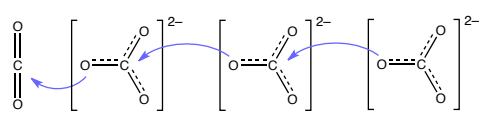

Figure 1. Oxo-Grotthus mechanism via a pyrocarbonate anion. (a) Formation of the pyrocarbonate ion $\mathrm{C}_{2} \mathrm{O}_{5}^{2-}$ out of the reaction of $\mathrm{CO}_{2}$ with the carbonate anion $\mathrm{CO}_{3}^{2-}$. (b) A cascading mechanism, with rapid sequence of pyrocarbonate formation and dissociation events.

\section{RESULTS AND DISCUSSION}

\section{Formation of pyrocarbonate anion}

We study by FPMD simulations the behaviour of one $\mathrm{CO}_{2}$ molecule in the $\mathrm{CaCO}_{3}$ solvent. From the analysis of the simulation trajectory, we observe the spontaneous formation of the pyrocarbonate ion $\mathrm{C}_{2} \mathrm{O}_{5}^{2-}$ out of the reaction of $\mathrm{CO}_{2}$ with the carbonate anion $\mathrm{CO}_{3}^{2-}$, as shown in Fig. 1(a). There is a rapid exchange between the species with multiple instances of formation and dissociation of the pyrocarbonate ion (79 events each in the simulation time span of $65 \mathrm{ps}$ ). In order to define the molecular species out of the FPMD simulation trajectory, it is necessary to use a distance criterion, usually determined by looking at the minimum of the pair radial distribution functions (RDFs). We have used a "hysteresis" criterion with minimal/maximal $\mathrm{C}-\mathrm{O}^{*}$ distances, where $\mathrm{O}^{*}$ is the central pyrocarbonate ion linking the two $\mathrm{C}$ atoms, $\mathrm{C}-\mathrm{O}^{*}-\mathrm{C}$ (the other oxygen atoms in pyrocarbonate are simply named $\mathrm{O}$ in the following), see Methods for further details. The minimal/maximal distances considered are $1.7 / 1.95 \AA$ since within this span the $\mathrm{C}-\mathrm{O}$ pair RDF is practically zero for molten carbonates.

With the mentioned criterion, we observe the presence of pyrocarbonate in the simulation box during $24.4 \%$ of the total simulation time. From this we can estimate a free energy of formation $\Delta A=R T \ln \left(\left(1-p_{\text {pyro }}\right) / p_{\text {pyro }}\right)=16.8 \pm 1.4 \mathrm{~kJ} . \mathrm{mol}^{-1}\left(R T=14.7 \mathrm{~kJ} . \mathrm{mol}^{-1}\right.$ at $T=1773 \mathrm{~K})$. The minimal/maximal intervals for the continual presence of $\mathrm{CO}_{2}$ or pyrocarbonate are respectively 0.024/4.84 ps and 0.016/1.52 ps. By analysing the histograms of the durations of $\mathrm{CO}_{2}$ or pyrocarbonate intervals, see Supplementary Figure 1, we estimate 
a $\mathrm{CO}_{2}$ average life time $\tau_{\mathrm{CO}_{2}}=0.88 \mathrm{ps}$ and a pyrocarbonate average life time $\tau_{\text {pyro }}=0.28 \mathrm{ps}$.

The snapshots in Fig. 2(a), 2(b) and 2(c) show respectively the approach of $\mathrm{CO}_{3}^{2-}$ to $\mathrm{CO}_{2}$, the formed pyrocarbonate, and its dissociation to $\mathrm{CO}_{3}^{2-}$ and $\mathrm{CO}_{2}$. As we can see in Fig. 2(d) the identity of the $\mathrm{C}$ atoms belonging to $\mathrm{CO}_{2}$ or pyrocarbonate varies along the simulation trajectory. We look then at all the pyrocarbonate formation/dissociation events and we keep track of the $\mathrm{C}$ atom part of the $\mathrm{CO}_{2}$ molecule before the formation of pyrocarbonate and after its dissociation. We find that $72.2 \%$ of the times the same $\mathrm{C}$ is part of $\mathrm{CO}_{2}$ before and after a pyrocarbonate ion time interval. Conversely, $27.8 \%$ of the times a different $\mathrm{C}$ atom composes $\mathrm{CO}_{2}$ after the dissociation of the pyrocarbonate.

To go further, we measure the correlation between events in which $\mathrm{C}$ has remained the same and between events in which $\mathrm{C}$ has changed. Given an event in which $\mathrm{C}$ has remained the same before the formation and after the dissociation of pyrocarbonate, we measure the frequency of occurrence of $n$ (after the first) consecutive events of the same kind. We measure the same for the events in which instead the $\mathrm{C}$ has changed before the formation and after the dissociation of pyrocarbonate. The results are shown in Fig. 2(e). Therein we also plot the theoretical curves $\gamma(1-\gamma)^{n}$ for "stay" events and $(1-\gamma) \gamma^{n}$ for "change" events, with $\gamma=p_{\text {stay } \rightarrow \text { change }}=p_{\text {stay }}(0)$, which assume no correlation between successive events. The probability of $n$ consecutive "stay" events is a slowly decaying function of $n$. Conversely, the probability of consecutive "change" events decays very rapidly, with a small probability of another change in $\mathrm{C}$ after the first one and a very small probability of having two changes after the first one. Therefore the cascading of $\mathrm{C}$ transfers, through a rapid succession of jump events (as in Fig. 1(b)) appears unlikely. Hence, in the carbonate melt, the transport of $\mathrm{CO}_{2}$ (free or bound in pyrocarbonate form) occurs via independent events of formation/dissociation of the pyrocarbonate molecule. This is similar to the Grotthuss mechanism in water, which involves the Zundel cation: $\mathrm{H}_{3} \mathrm{O}^{+}+\mathrm{H}_{2} \mathrm{O} \rightleftharpoons \mathrm{H}_{5} \mathrm{O}_{2}^{+}$, with oxygen playing the role of the proton. By a random walk model, we estimate the diffusion coefficient of carbon dioxide to be $D_{\text {Grotthuss }}=8.310^{-9} \mathrm{~m}^{2} \mathrm{~s}^{-1}$, i.e. 2.8 times faster than molecular diffusion of $\mathrm{CO}_{2}$ (see Supplementary Information for details). It would be of interest for future work to verify if in presence of an external electric field a cascade of $\mathrm{C}$ transfer is likely to occur, similarly to the correlated $\mathrm{H}$ transfers that have been observed in water under intense electric fields [19]. 


\section{Pyrocarbonate geometry}

Having observed that the pyrocarbonate ion exists in a significant portion of our simulation run, we then proceed to characterise its geometry by measuring distances and angles, whose distributions are shown in Fig. 3. We plot in Fig. 3(a) the distribution of the $\mathrm{C}-\mathrm{C}$, $\mathrm{C}-\mathrm{O}$ and $\mathrm{C}-\mathrm{O}^{*}$ distances. We observe how the $\mathrm{C}-\mathrm{O}$ distribution is quite narrow, peaking at about $1.26 \AA$, while the $\mathrm{C}-\mathrm{C}$ and $\mathrm{C}-\mathrm{O}^{*}$ distance distributions are quite wide. The latter has an asymmetric shape, which is related to the criterion chosen to define the pyrocarbonate molecule, see Methods for more details. In Fig. 3(b), we show the normalised distributions of the $\mathrm{C}-\mathrm{O}^{*}-\mathrm{C}, \mathrm{O}-\mathrm{C}-\mathrm{O}$ and $\mathrm{O}-\mathrm{C}-\mathrm{O}^{*}$ angles for pyrocarbonate. The $\mathrm{O}-\mathrm{C}-\mathrm{O}$ and $\mathrm{O}-\mathrm{C}-\mathrm{O}^{*}$ distributions are narrower, while the $\mathrm{C}-\mathrm{O}^{*}-\mathrm{C}$ shows a larger dispersion. This signals that the central $\mathrm{C}-\mathrm{O}^{*}-\mathrm{C}$ bridge is remarkably flexible. For comparison, we also show the $\mathrm{O}-\mathrm{C}-\mathrm{O}$ angle distribution for $\mathrm{CO}_{3}^{2-}$ molecules, which is narrow and peaks at about $120^{\circ}$. In the inset, see Fig. 3(c), we also show the logarithm of the normalised distribution of $\mathrm{O}-\mathrm{C}-\mathrm{O}$ angle of the $\mathrm{CO}_{2}$ molecule and we compare it with the case of $\mathrm{CO}_{2}$ in the gas phase (see Methods for further details). We remark that the fluctuations of the $\mathrm{O}-\mathrm{C}-\mathrm{O}$ angle are significantly enhanced in the condensed phase with respect to the gas phase. In fact the $\mathrm{O}-\mathrm{C}-\mathrm{O}$ angle can even bend to $\simeq 120^{\circ}$. Despite the low polarisability of $\mathrm{CO}_{2}$, we see here that the interactions with the surrounding medium, in this case composed of doubly charged cations and anions, can influence deeply the geometry of $\mathrm{CO}_{2}$. In particular, the bending of the $\mathrm{O}-\mathrm{C}-\mathrm{O}$ can be related to its interaction with $\mathrm{CO}_{3}^{2-}$ and the formation of the pyrocarbonate. Indeed in pyrocarbonate, we observe a $\mathrm{O}-\mathrm{C}-\mathrm{O}$ angle distribution peaking at about $130^{\circ}$.

Supplementary Table 1 compares the mean values of the distances and angles in the pyrocarbonate molecule as found in our study with those obtained in silicate melts [18] and in the gas phase, as studied by MP2 calculations by Peeters et al. [12]. The extracted values in the $\mathrm{CaCO}_{3}$ solvent are quite similar to what has been found in silicate melts. Therefore the geometry of the pyrocarbonate ions appears to stay approximately constant in ionic melts. In contrast, the central $\mathrm{C}-\mathrm{O}^{*}-\mathrm{C}$ angle is much more bent in the condensed phase with respect to the gas phase, by approximately $20^{\circ}$. Correspondingly, a smaller $\mathrm{C}-\mathrm{C}$ distance is found in the condensed phase. We attribute the bending of the pyrocarbonate ion to charge screening occurring in the condensed phase: the charge in the pyrocarbonate ion is mainly carried by the external $\mathrm{O}$ atoms, while the central $\mathrm{O}^{*}$ is mainly neutral, see for 
example the O-Ca RDFs shown in Supplementary Figure 2. Therefore, charge screening by the surrounding cations allows the charged molecular ends to get closer to each other, with respect to the gas phase. The $\mathrm{O}-\mathrm{C}-\mathrm{O}$ angle and consequently the $\mathrm{O}-\mathrm{C}-\mathrm{O}^{*}$ angle instead, remain quite similar to the gas phase case. To conclude the geometrical analysis on the pyrocarbonate ion, we calculate the $\mathrm{O}-\mathrm{C}-\mathrm{O}^{*}-\mathrm{C}$ dihedral angle, see Supplementary Figure 3. We find that the relative orientation in the molecule is rather disordered, probably due to the transients of formation of the pyrocarbonate molecule out of $\mathrm{CO}_{2}$ and the carbonate ion. However a preference for periplanar configurations can be observed.

\section{Solvation of molecular $\mathrm{CO}_{2}$}

Not only does $\mathrm{CO}_{2}$ form $\mathrm{C}_{2} \mathrm{O}_{5}^{2-}$ but even in its molecular state it exhibits specific interactions with $\mathrm{CO}_{3}^{2-}$. In order to characterise the solvation structure of molecular $\mathrm{CO}_{2}$, we build two-dimensional histograms of the structure around the $\mathrm{CO}_{2}$ molecule (see Methods for details). In Fig. 4(a), Fig. 4(b) and Fig. 4(c), we show these probability density maps for $\mathrm{C}, \mathrm{O}$ and $\mathrm{Ca}$ atoms respectively. To facilitate the visualisation and improve statistics, we neglect here the instantaneous bending of the $\mathrm{CO}_{2}$ molecule and we build the probability histograms in a cylindrical $\rho-\zeta$ coordinate system, where the $\hat{\boldsymbol{\zeta}}$ direction coincides with the $\mathrm{O}-\mathrm{O}$ unit vector and $\rho$ is the distance from the $\hat{\boldsymbol{\zeta}}$ axis. The zero of the coordinate system is taken at the mid-point of the $\mathrm{O}-\mathrm{O}$ vector, i.e. the average position of the $\mathrm{C}$ atom.

Looking at Fig. 4(a) and Fig. 4(b), we remark the existence of a preferred position for the solvation by $\mathrm{CO}_{3}^{2-}$ in the central area of the $\rho-\zeta$ representation. As a matter of fact the largest intensities for the $\mathrm{C}$ atoms are found in the region $2.75 \AA<\rho<3.90 \AA$ and $-1.85 \AA<\zeta<1.85 \AA$. For $\mathrm{O}$ atoms instead, we notice a bright spot in the area $2.25 \AA<\rho<3.00 \AA$ and $-0.55 \AA<\zeta<0.55 \AA$. In Supplementary Figure 4 we show the histogram of the number of $\mathrm{O}$ atoms found in the brightest region evidenced by Fig. 4(b). We find that the probability of having at least one $\mathrm{O}$ in that region is roughly $90 \%$. When we consider the central ovoidal red area, the probability of having more than three $\mathrm{O}$, thus necessarily more than one carbonate, is close to $80 \%$. This shows that the $\mathrm{CO}_{2}$ molecule is closely approached by carbonate anions on a preferred pathway, eventually leading to the formation of pyrocarbonate - similarly to what has been observed for $\mathrm{CO}_{2}$ in imidazolium acetates [20]. In order to get a clearer idea of the relative orientation of $\mathrm{CO}_{2}$ and carbonate 
in this precursor arrangement, we perform a gas phase geometry optimisation on a cluster composed of $\mathrm{CO}_{2}, \mathrm{CO}_{3}^{2-}$ and $\mathrm{Ca}^{2+}$ (see Methods). The resulting geometry is shown in Fig $4(\mathrm{~d})$. We find that one $\mathrm{O}$ of carbonate points directly to the $\mathrm{C}$ of $\mathrm{CO}_{2}$ with the $\mathrm{C}_{\mathrm{CO}_{2}}{ }^{-}$ $\mathrm{O}_{\text {carb. }}-\mathrm{C}_{\text {carb. }}$. angle being $\simeq 108^{\circ}$. The distances found in the gas phase are compatible with the two-dimensional colour chart of Fig. 4(b) although in the condensed phase the $\mathrm{C}_{\mathrm{CO}_{2}}{ }^{-}$ $\mathrm{O}_{\text {carb. }}-\mathrm{C}_{\text {carb. }}$ angle is closer to $\simeq 90^{\circ}$. In addition to this structural analysis, we present in Supplementary Figure 5 a view of the electronic state of the molecules during the formation of the pyrocarbonate, by looking at the centers of the maximally localized Wannier functions.

In Fig. 4(d) we see that a large excluded volume region is present for $\mathrm{Ca}$ atoms around the $\mathrm{CO}_{2}$ molecule. Interestingly, in the region corresponding to the brightest spot for $\mathrm{C}$ and $\mathrm{O}$, a dark spot is visible for Ca. However $\mathrm{Ca}$ does seem to play a role in the approach of carbonate to $\mathrm{CO}_{2}$. In fact, the position of $\mathrm{Ca}$ found in the gas phase (see Fig. 4(d)) corresponds to the intense region just outside the excluded volume. Small bright spots are also visible at $\rho \simeq 0$ and at distances (along $\hat{\boldsymbol{\zeta}}) 3-4$ times the $\mathrm{C}-\mathrm{O}$ distance $(\simeq 1.17 \AA$ ), where carbonate ions are already interposed to screen the $\mathrm{Ca}^{2+}$ charge.

\section{Pyrocarbonate solvation}

In contrast to the case of molecular $\mathrm{CO}_{2}$, the solvation structure of pyrocarbonate is more diffuse. Given the mostly periplanar symmetry indicated by the dihedral angle, see Supplementary Figure 3, we go on in neglecting one dimension and we produce two-dimensional histograms, in analogous way to what is shown in Fig. 4 for the $\mathrm{CO}_{2}$ molecule. In the present case, the vertical, $\hat{\boldsymbol{\zeta}}$ axis coincides with the $\mathrm{C}-\mathrm{C}$ direction, and $\rho$ is the distance from the this axis. The centre of the coordinate system is taken at the mid-point of the $\mathrm{C}-\mathrm{C}$ vector, see Methods for further details. We also keep track of the $\mathrm{C}$ atom being part of the $\mathrm{CO}_{2}$ molecule before the formation of the pyrocarbonate and we make the charts in such a way that the $\mathrm{C}$ formerly belonging to $\mathrm{CO}_{2}$ is always found at the bottom of the plots.

Fig. 5(a) shows the two-dimensional histograms for $\mathrm{C}$ atoms around the pyrocarbonate. We observe that the solvation of pyrocarbonate by $\mathrm{C}$ atoms is almost uniform with a small dent in the central region around $\zeta \simeq 0$ and $\rho \simeq 3$ corresponding to a modest electrostatic attraction by the central $\mathrm{O}^{*}$ atom of pyrocarbonate and the repulsion by the two $\mathrm{C}$ atoms. For the rest, we observe three consecutive solvation shells, with the first one being the most 
intense. In Fig. 5(b), we show the equivalent two-dimensional histogram for $\mathrm{O}$ atoms. Being $\mathrm{O}$ attached to $\mathrm{C}$ in carbonate ions units, the position of the $\mathrm{O}$ atoms follows from that of $\mathrm{C}$, although we see here that the situation for the $\mathrm{O}$ appears much more diffuse, corresponding to a random orientation of the plane of the carbonate molecules in the liquid phase. One small bright spot is visible at $\zeta \simeq-4.5$ and $\rho \simeq 0$. Since the $\mathrm{C}$ formerly in $\mathrm{CO}_{2}$ is, by construction, always found in the negative $\zeta$ portion, this possibly indicates that another $\mathrm{CO}_{3}^{2-}$ was or is in competition for the formation of pyrocarbonate. This is compatible with what shown in Supplementary Figure 4, where we have seen that the most intense spots in Fig. 4(b) correspond to one or two carbonate molecules close to $\mathrm{CO}_{2}$.

In Fig. 5(c), we show the two-dimensional histogram for Ca atoms. As in the case of $\mathrm{C}$ atoms, we observe an almost uniform first solvation shell with a central dent, corresponding to the attraction by the $\mathrm{O}^{*}$ atom and the repulsion by the $\mathrm{C}$ atoms of pyrocarbonate. Furthermore, we notice a small bright spot at $\rho \simeq 0, \zeta \simeq 4.5$, probably corresponding to the fact that $\mathrm{Ca}$ is close to the previous $\mathrm{CO}_{3}^{2-}$ unit, rather than to the previous $\mathrm{CO}_{2}$. Finally, in Fig. 5(d) we plot the three-dimensional isoprobability surfaces for the atoms composing the pyrocarbonate, derived from three-dimensional histograms calculated as described in Methods. The plot shows how the position of the $\mathrm{O}$ in pyrocarbonate is orientationally disordered in the condensed phase, probably due to the transients of formation/dissociation. When the isoprobability value is increased distinct spots appear that are consistent with periplanar configurations, $0^{\circ}<\phi<30^{\circ}$, or $150^{\circ}<\phi<180^{\circ}$, and with configurations with the two pairs of external $O$ nearly perpendicular to each other $80^{\circ}<\phi<110^{\circ}$, see also Supplementary Figure 3.

\section{Conclusions}

In conclusion, our study of carbon dioxide solvation in molten calcium carbonate by first principle molecular dynamics confirms the presence of the pyrocarbonate anion and of the equilibrium $\mathrm{CO}_{2}+\mathrm{CO}_{3}^{2-} \rightleftharpoons \mathrm{C}_{2} \mathrm{O}_{5}^{2-} \rightleftharpoons \mathrm{CO}_{3}^{2-}+\mathrm{CO}_{2}$. We have observed how the transport of $\mathrm{CO}_{2}$ in molten carbonate occurs in a similar fashion to the Grotthuss mechanism in water: we name this mechanism oxo-Grotthuss mechanism. We have characterised the geometry of pyrocarbonate and found it has a periplanar configuration, with the central $\mathrm{C}-\mathrm{O}^{*}-\mathrm{C}$ bridge much more bent than in the gas phase, due to charge screening by the counterions. 
Furthermore, we have observed that the interaction between $\mathrm{CO}_{2}$ and $\mathrm{CO}_{3}^{2-}$ leading to the formation of pyrocarbonate occurs along a preferred pathway with the carbonate ion approaching $\mathrm{CO}_{2}$ "laterally". The enhanced transport of $\mathrm{CO}_{2}$ by $\mathrm{O}^{2-}$ exchange - three times faster than molecular diffusion - may also explain the diffusivity of $\mathrm{CO}_{2}$ in mixed oxide-carbonate materials [15].

The $\mathrm{CO}_{2} / \mathrm{CO}_{3}^{2-}$ equilibrium can also be described in the framework of oxo-acidity, with $\mathrm{CO}_{2}$ being the acid and $\mathrm{CO}_{3}^{2-}$ its conjugated base. In this context, Grotthuss-like transport may be rather general when an acid is dissolved in its conjugated base.

\section{METHODS}

\section{First-principles molecular dynamics simulations}

We study a system originally composed of $127 \mathrm{CO}_{3}^{2-}$ carbonate anions, $127 \mathrm{Ca}^{2+}$ calcium cations and one $\mathrm{CO}_{2}$ molecule (638 atoms, 4080 valence electrons). We fix the side of cubic simulation box to $L=20.054 \AA$, which gives a density of $\rho=2.63 \mathrm{~g} . \mathrm{cm}^{-3}$. The $\mathrm{CO}_{2}$ concentration is thus $0.206 \mathrm{~mol} \mathrm{~L}^{-1}$, a value typical for alkali molten salts under 1 atm of $\mathrm{CO}_{2}[21]$. We set the temperature, controlled by the Nosé-Hoover thermostat chain [22, 23] with time constant $\tau=0.5 \mathrm{ps}$, at $T=1773 \mathrm{~K}$. This thermodynamic point is located, according to the pure $\mathrm{CaCO}_{3}$ melting curve obtained by Suito et al. [24] and Spivak et al. [25], along the melting curve of disordered pure calcite $\left(\right.$ no $\left.\mathrm{CO}_{2}\right)$.

We perform FPMD simulations based on DFT and the Born-Oppenheimer dynamics. We use the software CP2K [26] and in particular the Quickstep algorithm [27]. The latter employs a hybrid Gaussian plane-wave method (GPW) [28]. We use the Goedecker-TeterHutter (GTH) norm-conserving pseudo-potentials [29-31] to replace the core electrons. We cut off the electronic density at 400 Ry and use NN50 smoothing for applying the exchangecorrelation potential. For $\mathrm{C}$ and $\mathrm{O}$ atoms, we use a triple-zeta valence doubly polarised (TZV2P) basis set [32]. For Ca atoms, we use a double-zeta valence plus polarisation (DZVP) basis set optimised for molecules [33]. The exchange-correlation interactions are taken into account by the gradient-corrected BLYP functional [34, 35]. We add dispersive interactions corrections by using the DFT-D2 scheme [36], with a cutoff of $40 \AA$.

The starting configuration has been taken from previous equilibrated FPMD simulations 
of the pure liquid $\mathrm{CaCO}_{3}$ (128 units) [17] after having replaced one $\mathrm{CO}_{3}^{2-}$ with $\mathrm{CO}_{2}$ and having erased one $\mathrm{Ca}^{2+}$ from the simulation box. As mentioned earlier, we run the simulation in the canonical $N V T$ ensemble, with the simulation time step set to $0.5 \mathrm{fs}$ and periodic boundary conditions. We store the trajectory at every time step for post-run-time analysis. We accumulate the trajectory for approximately 65 ps (130000 simulation steps).

In addition, we also perform a FPMD simulation of $\mathrm{CO}_{2}$ in the gas phase, as well as geometry optimisations of the pyrocarbonate ion in the gas phase and a cluster composed of $\mathrm{CO}_{2}, \mathrm{CO}_{3}^{2-}$ and $\mathrm{Ca}^{2+}$ (shown in Fig. 4(d)). Details for these can be found in Supplementary Information.

\section{Analysis}

We perform the analysis of the simulation trajectory by using an in-house analysis suite. In order to define molecules from the atomic positions at each time step, we use a depth first search (DFS) closure algorithm [37]. We use a particular "hysteresis" criterion in order to define whether in a given time frame, we have molecular $\mathrm{CO}_{2}$ or pyrocarbonate ion. If we have molecular $\mathrm{CO}_{2}$ in the previous time frame, we account for the formation of the pyrocarbonate in the current frame only when the $\mathrm{C}-\mathrm{O}^{*}$ distance is less than $1.7 \AA$. On the other hand, if we have pyrocarbonate in the previous frame, we account for a dissociation event in the current frame only when the $\mathrm{C}-\mathrm{O}^{*}$ distance becomes larger than $1.95 \AA$. This criterion allows smoothing out the behaviour that is observed when a simple distance cutoff criterion is used and it is inspired to the criteria used for correlations in H-bonds dynamics in water [38].

To build the two-dimensional colour charts around the $\mathrm{CO}_{2}$ molecules (see Fig. 4), we first recenter the coordinates, with the centre $\mathbf{r}_{c}$ defined as the mid-point of the $\mathrm{CO}_{2} \mathrm{O}-\mathrm{O}$ vector. We define the $\hat{\boldsymbol{\zeta}}$ direction as the $\mathrm{O}-\mathrm{O}$ unit vector. We then calculate the coordinate $\zeta$ of a given atom as $\zeta=\mathbf{r}_{i}^{\prime} \cdot \hat{\boldsymbol{\zeta}}$, where $\mathbf{r}_{i}^{\prime}=\mathbf{r}_{i}-\mathbf{r}_{c}$. The coordinate $\rho$ is given by $\rho=\sqrt{\left\|\mathbf{r}_{i}{ }_{i}\right\|^{2}-\zeta^{2}}$ or equivalently by $\rho=\left\|\mathbf{r}_{i}^{\prime}-\zeta \hat{\boldsymbol{\zeta}}\right\|$. We bin the space by $\Delta \zeta=\Delta \rho=0.1 \AA$ in the intervals between $-L / 2$ and $L / 2$ for $\zeta$ and 0 and $\sqrt{2} L / 2$ for $\rho$. We normalise the two-dimensional intensity histogram dividing by the product of the number of steps, the number of particles of type $\alpha$, with $\alpha=\mathrm{C}$, O, Ca, and the bin volume $2 \pi \rho \Delta \rho \Delta \zeta$.

For the construction of the two-dimensional colour charts around the pyrocarbonate ion 
(see Fig. 5), we follow an analogous procedure, with the only difference that now the $\mathrm{C}-\mathrm{C}$ direction is taken as $\hat{\boldsymbol{\zeta}}$ and the mid-point of the $\mathrm{C}-\mathrm{C}$ vector as centre. Furthermore, we specifically take the beginning of the $\mathrm{C}-\mathrm{C}$ vector corresponding to the $\mathrm{C}$ atom that was part of the $\mathrm{CO}_{2}$ molecule just before the formation of the pyrocarbanate ion. Therefore the former $\mathrm{C}$ of the $\mathrm{CO}_{2}$ molecule is always found in the negative $\zeta$ portion of the plots.

We have also built three dimensional colour charts for C, O and Ca (see for example Fig. $5(\mathrm{~d}))$. In those plots, the axis $\hat{\boldsymbol{\zeta}}$ coincides with the $\mathrm{C}-\mathrm{C}$ direction, the $\hat{\boldsymbol{v}}$ axis is obtained from $\mathbf{C O}^{*}-\left(\mathbf{C O}^{*} \cdot \hat{\boldsymbol{\zeta}}\right) \hat{\boldsymbol{\zeta}}$ and $\hat{\boldsymbol{\xi}}=\hat{\boldsymbol{v}} \times \hat{\boldsymbol{\zeta}}$. We recenter the coordinates around the mid-point of the C-C vector $\mathbf{r}_{c}, \mathbf{r}_{i}^{\prime}=\mathbf{r}_{i}-\mathbf{r}_{c}$. The new coordinates are thus $\xi=\mathbf{r}_{i}^{\prime} \cdot \hat{\boldsymbol{\xi}}, v=\mathbf{r}_{i}^{\prime} \cdot \hat{\boldsymbol{v}}$ and $\zeta=\mathbf{r}^{\prime}{ }_{i} \cdot \hat{\boldsymbol{\zeta}}$. We bin the space by $\Delta \xi=\Delta v=\Delta \zeta=0.1 \AA$ between $-6.0 \AA$ and $6.0 \AA$. We normalise the intensity histograms by dividing by the number of steps, the number of particles of type $\alpha(\alpha=\mathrm{C}, \mathrm{O}, \mathrm{Ca})$, and by the volume of the bin $\Delta \xi \Delta v \Delta \zeta$. Molecular representations and iso-probability surfaces are visualised using the software VMD [39].

[1] Gaillard, F., Malki, M., Iacono-Marziano, G., Pichavant, M. \& Scaillet, B. Carbonatite Melts and Electrical Conductivity in the Asthenosphere. Science 322, 1363-1365 (2008).

[2] Jones, A. P., Genge, M. \& Carmody, L. Carbonate Melts and Carbonatites. Rev. Mineral. Geochem. 75, 289-322 (2013).

[3] Kaminsky, F., Wirth, R., Schreiber, A \& Thomas, R. Nyerereite and nahcolite inclusions in diamond: evidence for lower-mantle carbonatitic melts. Mineral. Mag. 73, 797-816 (2009).

[4] Stoppa, F., Jones, A. P. \& Sharygin, V. Nyerereite from carbonatite rocks at Vulture volcano: implications for mantle metasomatism and petrogenesis of alkali carbonate melts. Cent. Euro. J. Geosci. 1, 131-151 (2009).

[5] Kaminsky, F. Mineralogy of the lower mantle: A review of 'super-deep' mineral inclusions in diamond. Earth Sci. Rev. 110, 127-147 (2012).

[6] Dasgupta, R. \& Hirschmann, M. M. The deep carbon cycle and melting in Earth's interior Earth Planet. Sci. Lett. 298, 1-13 (2010).

[7] Dasgupta, R. \& Hirschmann, M. M. Melting in Earth's deep upper mantle caused by carbon dioxide. Nature 440, 659-662 (2006).

[8] Chery, D., Lair, V. \& Cassir, M. $\mathrm{CO}_{2}$ electrochemical reduction into $\mathrm{CO}$ or $\mathrm{C}$ in molten 
carbonates: a thermodynamic point of view. Electrochim. Acta 160, 74-81 (2015).

[9] Chery, D., Albin, V., Lair, V. \& Cassir, M. Thermodynamic and experimental approach of electrochemical reduction of $\mathrm{CO}_{2}$ in molten carbonates. Int. J. Hydrogen Energy 39, 1233012339 (2014).

[10] Kanai, Y., Fukunaga, K., Terasaka, K. \& Fujioka, S. Mass transfer in molten salt and suspended molten salt in bubble column. Chem. Eng. Sci. 100, 153-159 (2013).

[11] Claes, P., Moyaux, D. \& Peeters, D. Solubility and Solvation of Carbon Dioxide in the Molten $\mathrm{Li}_{2} \mathrm{CO}_{3} / \mathrm{Na}_{2} \mathrm{CO}_{3} / \mathrm{K}_{2} \mathrm{CO}_{3}$ (43.5:31.5:25.0 mol-\%) Eutectic Mixture at 973 K. I. Experimental Part. Eur. J. Inorg. Chem. 1999, 583-588 (1999).

[12] D. Peeters, D. Moyaux \& P. Claes. Solubility and Solvation of Carbon Dioxide in the Molten $\mathrm{Li}_{2} \mathrm{CO}_{3} / \mathrm{Na}_{2} \mathrm{CO}_{3} / \mathrm{K}_{2} \mathrm{CO}_{3}$ (43.5:31.5:25.0 mol-\%) Eutectic Mixture at $973 \mathrm{~K}$. II. Theoretical Part. Eur. J. Inorg. Chem. 1999, 589-592 (1999).

[13] Burna. P. J., Grein, F. \& Passmore, J. Density functional theory (DFT) calculations on the structures and stabilities of $\left[\mathrm{C}_{n} \mathrm{O}_{2 n+1}\right]^{2-}$ and $\left[\mathrm{C}_{n} \mathrm{O}_{2 n+1}\right] \mathrm{X}_{2}$ polycarbonates containing chainlike $\left(\mathrm{CO}_{2}\right)_{n}$ units $(n=2-6 ; \mathrm{X}=\mathrm{H}$ or Li). Can. J. Chem. 89, 671-687 (2011).

[14] Frapper, G. \& Saillard, J.-Y. Search for New Allotropic Forms of Carbon Dioxide and Carbon Disulfide: A Density Functional Study of $\mathrm{CX}_{2}$-Based Oligomers $(\mathrm{X}=\mathrm{O}, \mathrm{S})$. J. Am. Chem. Soc. 122, 5367-5370 (2000).

[15] Zhang, L. et al. First spectroscopic identification of pyrocarbonate for high $\mathrm{CO}_{2}$ flux membranes containing highly interconnected three dimensional ionic channels. Phys. Chem. Chem. Phys. 15, 13147-13152 (2013).

[16] Zeller, K.-P., Schuler, P. \& Haiss, P. The Hidden Equilibrium in Aqueous Sodium Carbonate Solutions - Evidence for the Formation of the Dicarbonate Anion. Eur. J. Inorg. Chem. 2005, $168-172(2005)$.

[17] Vuilleumier, R., Seitsonen, A., Sator, N. \& Guillot, B. Structure, equation of state and transport properties of molten calcium carbonate $\left(\mathrm{CaCO}_{3}\right)$ by atomistic simulations. Geochim. Cosmochim. Ac. 141. 547-566 (2014).

[18] Vuilleumier, R., Seitsonen, A. P., Sator, N. \& Guillot, B. Carbon dioxide in silicate melts at upper mantle conditions: Insights from atomistic simulations. Chem. Geol. xx, xx-xx (2015). DOI: http://dx.doi.org/10.1016/j.chemgeo.2015.02.027

[19] Saitta, A. M., Saija, F. \& Giaquinta, P. V. Ab Initio Molecular Dynamics Study of Dissociation 
of Water under an Electric Field. Phys. Rev. Lett. 108, 207801 (2012).

[20] Kelemen, Z. et al. An Abnormal N-Heterocyclic Carbene-Carbon Dioxide Adduct from Imidazolium Acetate Ionic Liquids: The Importance of Basicity. Chem. Eur. J. 20, 13002-13008 (2014).

[21] Chery, D., Lair, V. \& Cassir, M. Overview on $\mathrm{CO}_{2}$ valorization: challenge of molten carbonates. Front. Energy Res. 3, 43 (2015).

[22] Nosé, S. A molecular-dynamics method for simulations in the canonical ensemble. Mol. Phys. 52, 255-268 (1984).

[23] Nosé, S. A unified formulation of the constant temperature molecular-dynamics methods. $J$. Chem. Phys. 81, 511-519 (1984).

[24] Suito, K. et al. Phase relations of $\mathrm{CaCO}_{3}$ at high pressure and high temperature. Am. Mineral. 86, 997-1002 (2001).

[25] Spivak, A. V., Litvin, Yu. A., Ovsyannikov, S. V., Dubrovinskaia, N. A. \& Dubrovinsky L. S. Stability and breakdown of $\mathrm{Ca}^{13} \mathrm{CO}_{3}$ melt associated with formation of ${ }^{13} \mathrm{C}$-diamond in static high pressure experiments up to 43 GPa and 3900 K. Solid State Chem. 191, 102-106 (2012).

[26] Hutter, J., Iannuzzi, M., Schiffmann, F. \& VandeVondele, J. CP2K: atomistic simulations of condensed matter systems. WIREs Comput. Mol. Sci. 4, 15-25 (2014).

[27] VandeVondele, J. et al. QUICKSTEP: Fast and accurate density functional calculations using a mixed Gaussian and plane waves. Comp. Phys. Commun. 167, 103-128 (2005).

[28] Lippert, G., Hutter J. \& Parrinello M. A hybrid gaussian and plane wave density functional scheme. Mol. Phys. 92, 477-487 (1997).

[29] Goedecker, S., Teter, M. \& Hutter, J. Separable dual-space Gaussian pseudopotentials. Phys. Rev. B 54, 1703-1710 (1996).

[30] Hartwigsen, C., Goedecker, S. \& Hutter J. Relativistic separable dual-space Gaussian pseudopotentials from H to Rn. Phys. Rev. B 58, 3641-3662 (1998).

[31] Krack, M. Pseudopotentials for H to Kr optimized for gradient-corrected exchange-correlation functionals. Theor. Chem. Acc. 114, 145-152 (2005).

[32] VandeVondele, J. et al. The influence of temperature and density functional models in ab initio molecular dynamics simulation of liquid water. J. Chem. Phys. 122, 014515 (2005).

[33] VandeVondele, J. \& Hutter, J. Gaussian basis sets for accurate calculations on molecular systems in gas and condensed phases. J. Chem. Phys. 127, 114105 (2007). 
[34] Becke, A. D. Density-functional exchange-energy approximation with correct asymptotic behavior. Phys. Rev. A 38, 3098-3100 (1988).

[35] Lee, C., Yang, W. \& Parr R. G. Development of the Colle-Salvetti correlation energy formula into a functional of the electron density. Phys. Rev. B 37, 785-789 (1988).

[36] Grimme, S. Semiempirical GGA-type density functional constructed with a long-range dispersion correction. J. Comput. Chem. 27, 1787-1799 (2006).

[37] Cormen, T. H., Leiserson, C. E., Rivest, R. L. \& Stein, C. Introduction to Algorithms (MIT Press, Cambridge, Massachusetts, USA, 1990).

[38] Laage, D. \& Hynes, J. T. A Molecular Jump Mechanism of Water Reorientation. Science 311, 832-835 (2006).

[39] Humphrey, W., Dalke, A. \& Schulten, K. VMD - Visual Molecular Dynamics. J. Molec. Graphics, 14, 33-38 (1996).

\section{ACKNOWLEDGEMENTS}

We thank Michel Cassir, Virginie Lair, Bertrand Guillot, Fabrice Gaillard, Volker Haigis and Anne Boutin for fruitful discussions. The research reported herein was funded by PSL Research University (project COOCAR, grant ANR-10-IDEX-0001-02) and Agence Nationale pour la Recherche (project ELECTROLITH, grant ANR-2010-BLAN-621-03). This work has been performed using HPC resources from GENCI (grants 2013-082309, 2014-082309 and 2015-082309) and IDRIS (grant "Grand Challenge" 100577). We also acknowledge PRACE for awarding us access to resource Curie based in France at CEA Bruyères-le-Chatel (preparatory access allocation 2010PA2746).

\section{AUTHOR CONTRIBUTIONS}

R. V. performed the FPMD simulations, D. C. analysed the trajectories, prepared the figures and wrote the manuscript. All authors designed research, discussed the results and revised the manuscript. 


\section{ADDITIONAL INFORMATION}

Correspondence and requests for materials should be addressed to F.-X.C. or R.V.

\section{Competing financial interests}

The authors declare no competing financial interests. 
(a)

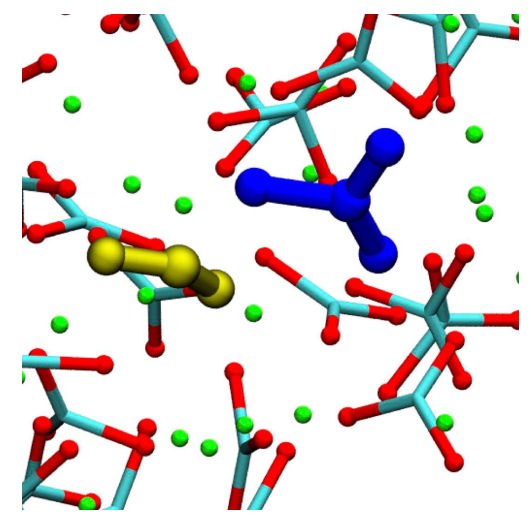

(d)

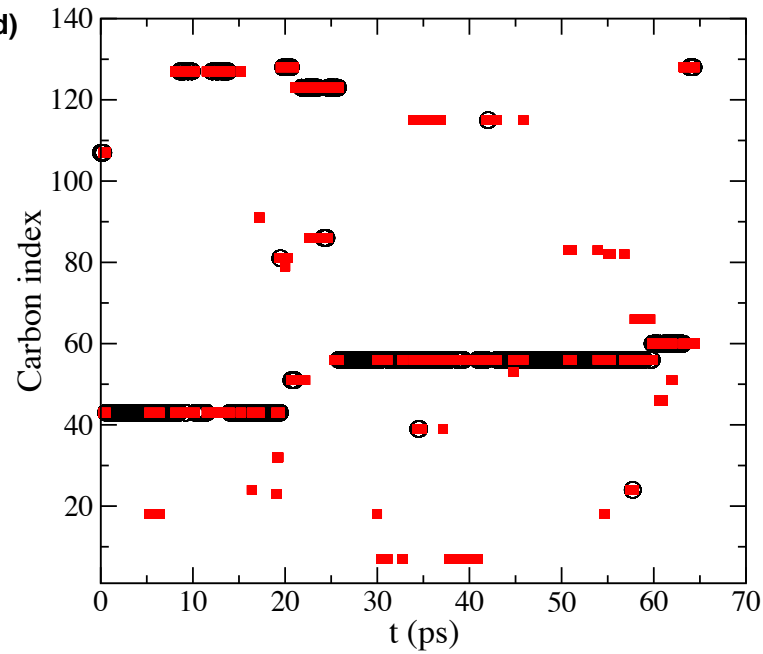

(b)

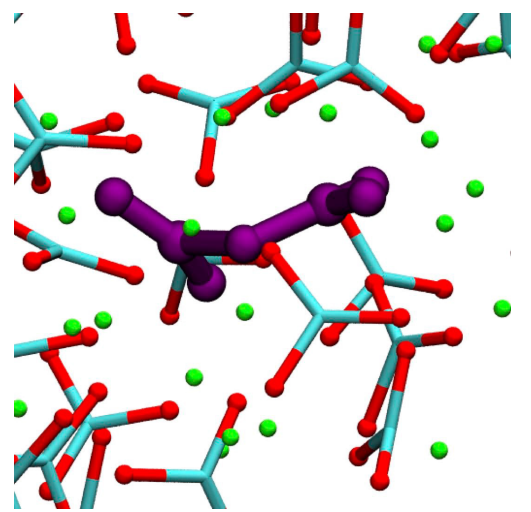

(c)

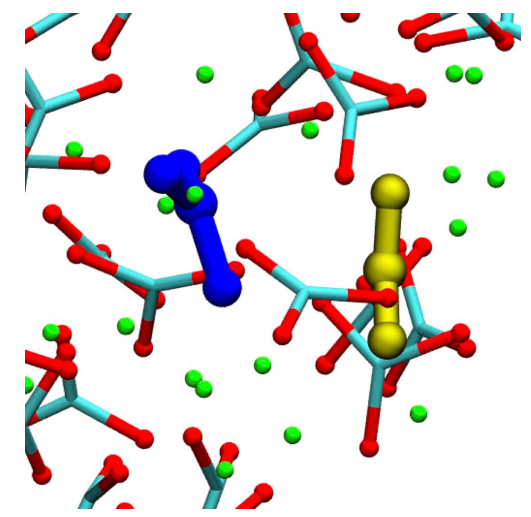

(e)

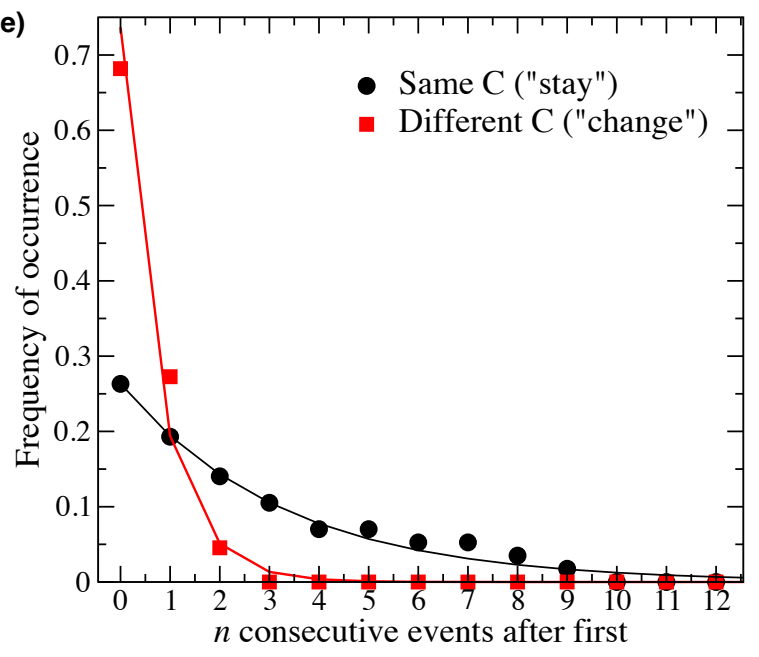

Figure 2. Formation/dissociation of pyrocarbonate and $\mathbf{C}$ transport. The snapshots in (a), (b), (c) represent one instance of the formation/dissociation of pyrocarbonate during the simulation run. In (a) $\mathrm{CO}_{2}$ and $\mathrm{CO}_{3}^{2-}$ approach, in (b) pyrocarbonate $\mathrm{C}_{2} \mathrm{O}_{5}^{2-}$ is formed, and in (c) pyrocarbonate dissociates into $\mathrm{CO}_{3}^{2-}$ and $\mathrm{CO}_{2}$. Carbonate molecules in the solvent are represented by cyan/red sticks and red spheres for $\mathrm{O}$ atoms, $\mathrm{Ca}$ atoms are represented as green spheres. The $\mathrm{CO}_{2}$ molecule is shown in yellow, the $\mathrm{CO}_{3}^{2-}$ molecule in blue and pyrocarbonate in purple. Panel (d) shows the indices of the $\mathrm{C}$ atoms in $\mathrm{CO}_{2}$ (black) and pyrocarbonate (red) along the simulation. In panel (e) we follow the $\mathrm{C}$ atom in $\mathrm{CO}_{2}$ before the formation and after the dissociation of pyrocarbonate; we plot in black the probability of that carbon atom staying $n$ consecutive times the same (always reforming the same $\mathrm{CO}_{2}$ molecule), and in red that of changing $n$ consecutive times (cascading $\mathrm{C}$ transfers). The lines are as described in the text. 

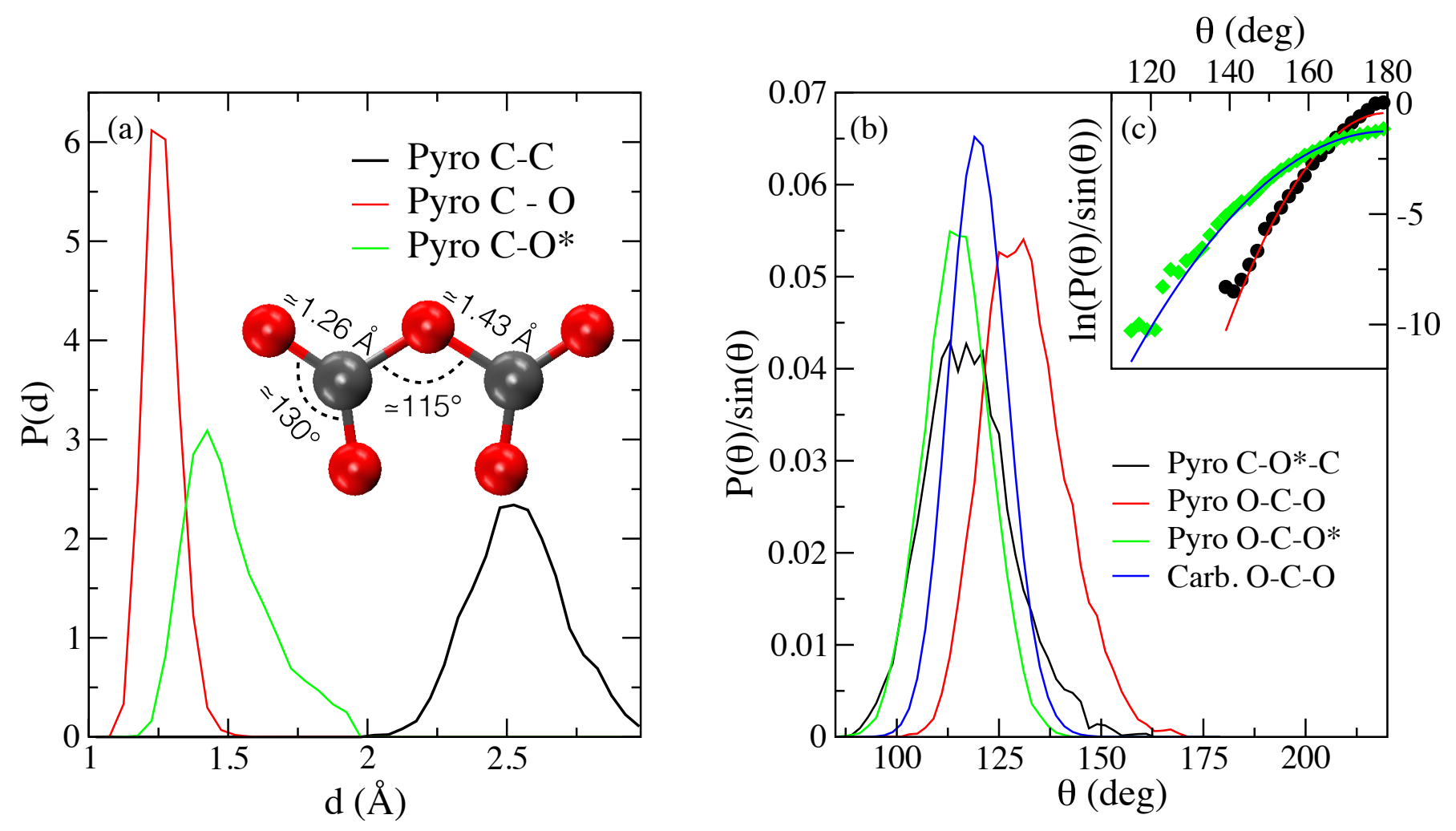

Figure 3. Geometry of the pyrocarbonate anion. (a) Distribution of the $\mathrm{C}-\mathrm{C}, \mathrm{C}-\mathrm{O}$ and C-O* distances measured during the time intervals of existence of $\mathrm{C}_{2} \mathrm{O}_{5}^{2-}$. Inset: average geometry of pyrocarbonate (O: red; $\mathrm{C}$ : grey), with values of the $\mathrm{C}-\mathrm{O}^{*}$ and $\mathrm{C}-\mathrm{O}$ distances and $\mathrm{C}-\mathrm{O}^{*}-\mathrm{C}$ and $\mathrm{O}-\mathrm{C}-\mathrm{O}$ angles shown. (b) Distribution of the $\mathrm{C}-\mathrm{O}^{*}-\mathrm{C}, \mathrm{O}-\mathrm{C}-\mathrm{O}, \mathrm{O}-\mathrm{C}-\mathrm{O}^{*}$ for the pyrocarbonate ion. For comparison, we also plot the distribution of the $\mathrm{O}-\mathrm{C}-\mathrm{O}$ angle in $\mathrm{CO}_{3}^{2-}$. We normalise the distributions by dividing by $\sin \theta$. (c) Natural logarithm of the distribution of the $\mathrm{O}-\mathrm{C}-\mathrm{O}$ angle in $\mathrm{CO}_{2}$ during the intervals in which it is present in the $\mathrm{CaCO}_{3}$ melt (green diamonds) and we compare it to its behaviour in the gas phase (black circles), see Methods. We also perform a parabolic fit of the form $A(\theta-180)^{2}+B$. The fits are shown as blue and red solid lines for the $\mathrm{CaCO}_{3}$ and gas phase cases respectively. The values of the parameters extracted are: $A=-0.0025$, $B=-1.25\left(\mathrm{CaCO}_{3}\right)$ and $A=-0.0059, B=-0.42$ (gas). 

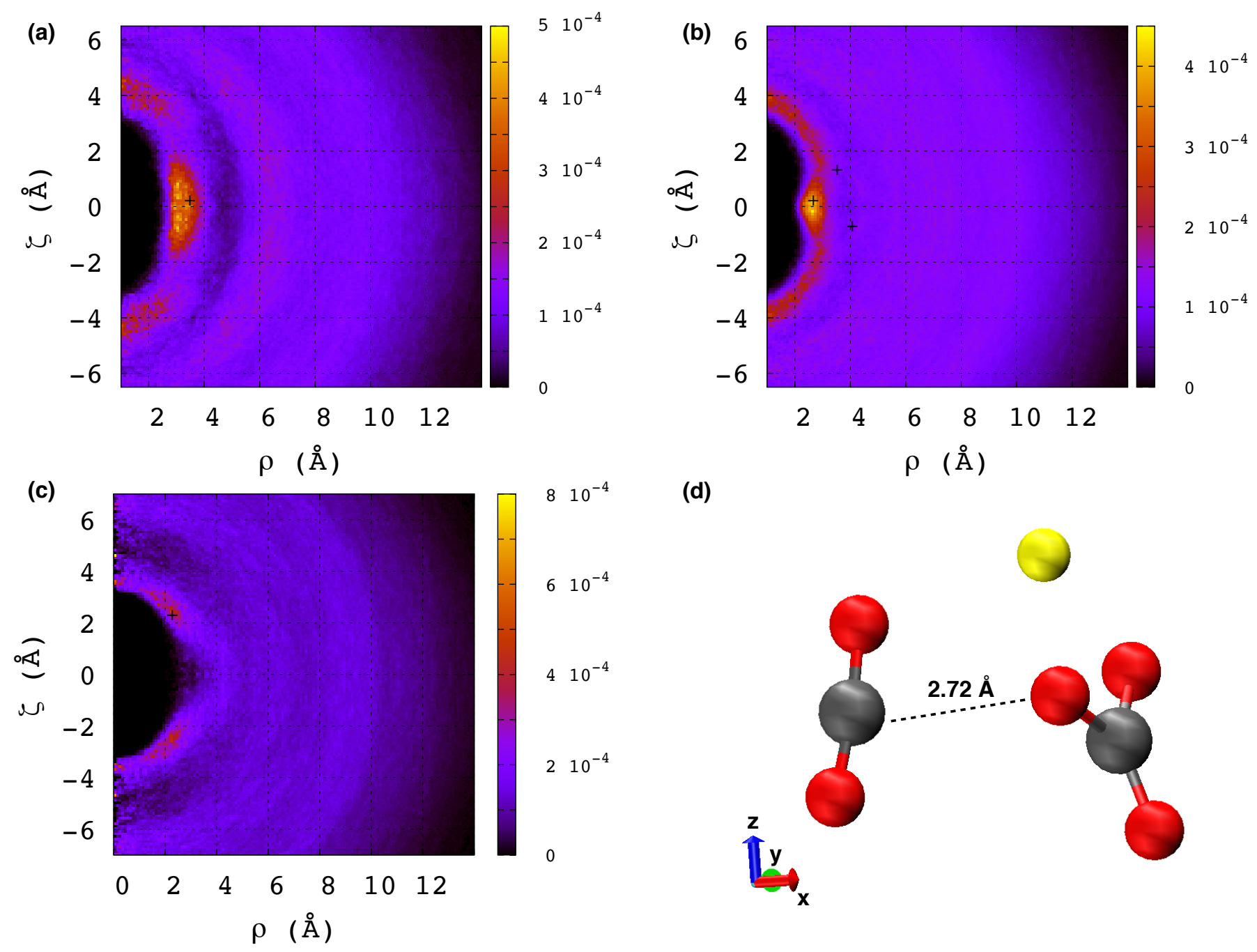

(d)

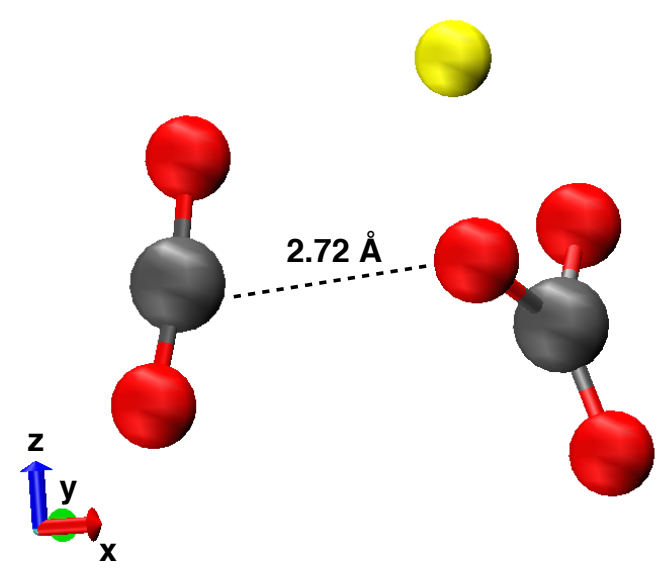

Figure 4. Solvation structure around the $\mathrm{CO}_{2}$ molecule. We build two-dimensional colour charts (see Methods) around the $\mathrm{CO}_{2}$ molecule for (a) $\mathrm{C}$ atoms, (b) $\mathrm{O}$ atoms and (c) Ca atoms. In the plots the $\mathrm{CO}_{2}$ molecule is oriented with its $\mathrm{O}-\mathrm{O}$ axis along the $\hat{\boldsymbol{\zeta}}$ direction, with $\zeta=0$ being the mid-point of the $\mathrm{O}-\mathrm{O}$ distance. Therefore $\zeta$ is the projection of an atom position along the $\mathrm{O}-\mathrm{O}$ axis, while $\rho$ is its distance from the $\mathrm{O}-\mathrm{O}$ axis. (d) Gas phase geometry obtained for a cluster composed of $\mathrm{CO}_{2}, \mathrm{CO}_{3}^{2-}$ and $\mathrm{Ca}^{2+}$ (see Methods). The Cartesian axes are shown at the bottom, $\mathrm{C}$ is represented in grey, $\mathrm{O}$ in red and $\mathrm{Ca}$ in yellow. The positions of the atoms of carbonate and Ca in the gas phase are marked as + symbols in the respective plots for the condensed phase. Distances are measured in $\AA$. 

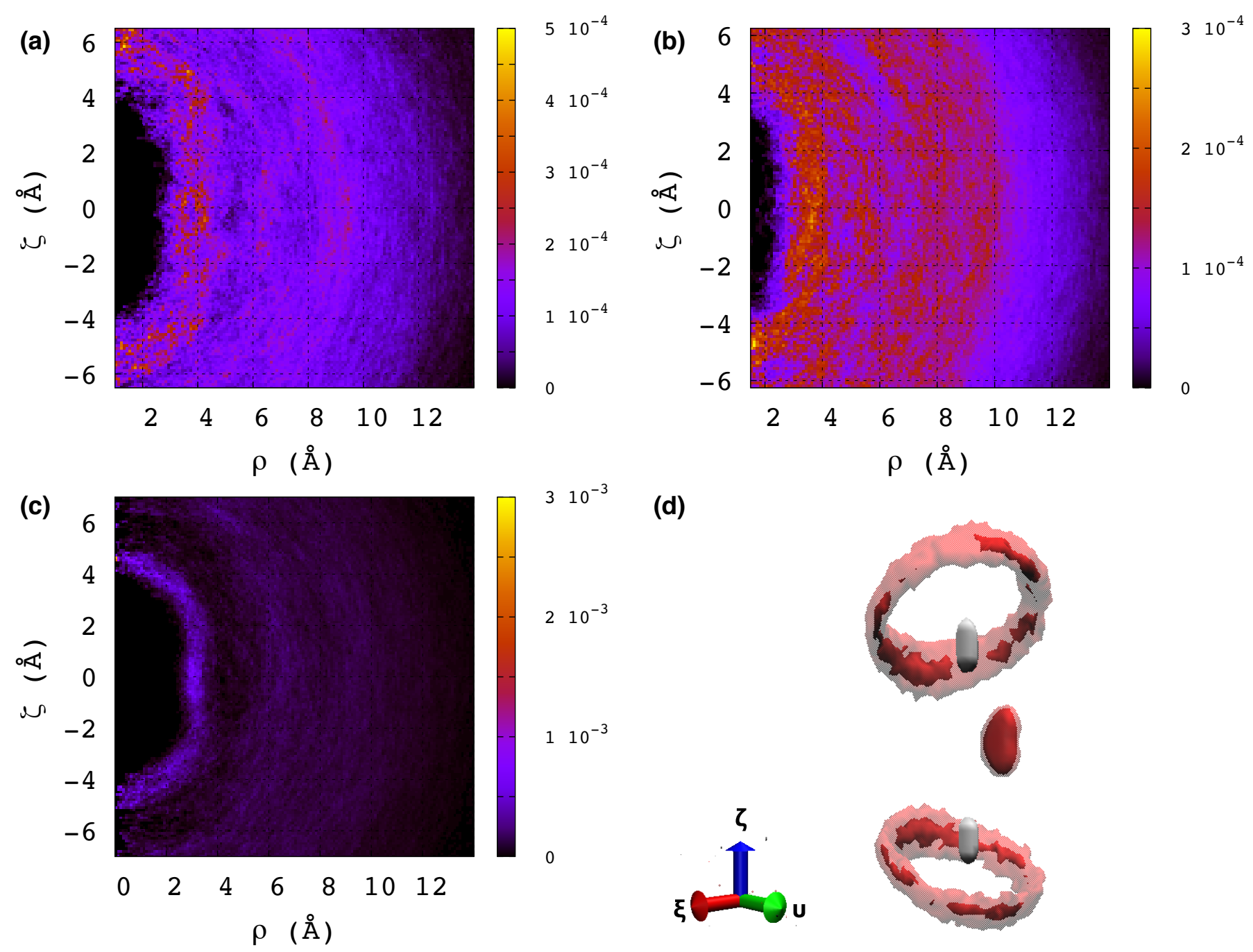

(d)

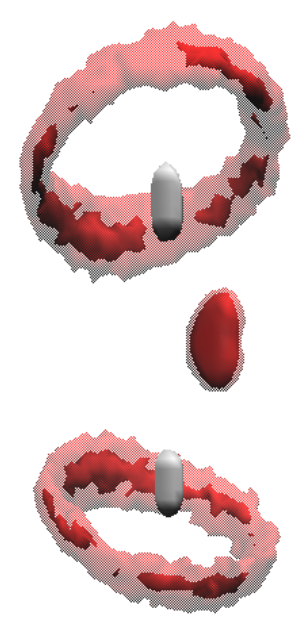

Figure 5. Solvation structure around the pyrocarbonate ion. We build two-dimensional colour charts (see Methods) around the pyrocarbonate molecule for (a) $\mathrm{C}$ atoms, (b) $\mathrm{O}$ atoms and (c) Ca atoms. In the plots the $\mathrm{C}_{2} \mathrm{O}_{5}^{2-}$ molecule is oriented with its $\mathrm{C}-\mathrm{C}$ axis along the $\hat{\zeta}$ direction, with $\zeta=0$ being the mid-point of the $\mathrm{C}-\mathrm{C}$ vector. Therefore $\zeta$ is the projection of an atom position along the $\mathrm{C}-\mathrm{C}$ axis, while $\rho$ is its distance from the $\mathrm{C}-\mathrm{C}$ axis. The former $\mathrm{C}$ of the $\mathrm{CO}_{2}$ molecule is always placed in the negative $\zeta$ portion of the plots. (d) Three-dimensional colour chart of the pyrocarbonate molecule (see Methods). Here the $\hat{\boldsymbol{\zeta}}$ direction coincides with the $\mathrm{C}-\mathrm{C}$ axis, the $\hat{\boldsymbol{v}}$ direction is the perpendicular to $\hat{\boldsymbol{\zeta}}$ passing by $\mathrm{O}^{*}$ and $\hat{\boldsymbol{\xi}}=\hat{\boldsymbol{v}} \times \hat{\boldsymbol{\zeta}}$. We plot the iso-probability surfaces corresponding to $P=0.005$ for $\mathrm{C}$ (grey), $P=0.002$ for $\mathrm{O}$ (transparent red) and $P=0.007$ for $\mathrm{O}$ (solid red). Distances are measured in $\AA$. 


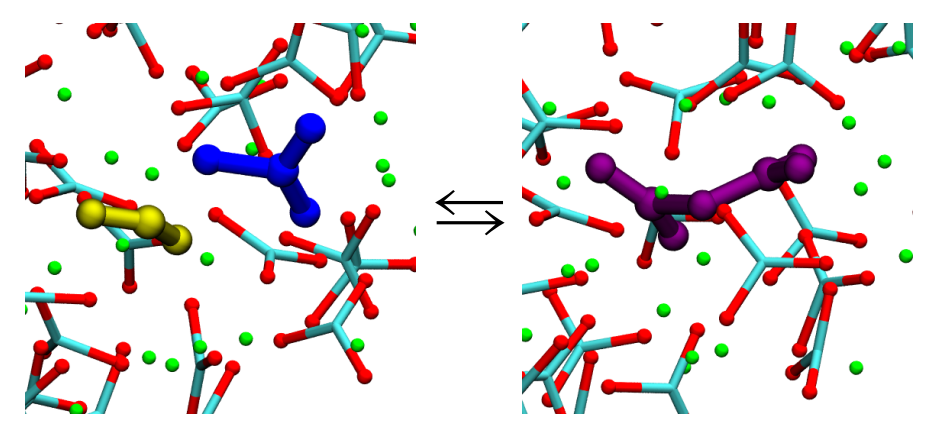

Table of contents graphic

\section{Table of contents summary:}

First principles molecular dynamics simulations have shown that solvation of carbon dioxide in molten calcium carbonate leads to the formation of the pyrocarbonate anion, $\mathrm{C}_{2} \mathrm{O}_{5}^{2-}$. Despite its short life time, the formation of the pyrocarbonate anion significantly impacts the transport of $\mathrm{CO}_{2}$, which occurs in a fashion similar to the Grotthuss mechanism in water. 